\title{
Role of static and dynamic MRI in evaluation of pelvic posterior compartment pathologies: prospective case series
}

\author{
Dina G. Abdelzaher ${ }^{1 *}$, Mahmoud Abdelatif ${ }^{1}$, Waleed M. Thabet ${ }^{2}$, Amr M. Elshafei $^{3}$ and Magda M. Shady ${ }^{1}$
}

\begin{abstract}
Background: Pelvic floor dysfunction affects the lifestyle of women worldwide; the aim of this study is to evaluate the role of static MRI and dynamic MR defecography in the diagnosis of the posterior compartment of pelvic floor dysfunction.

This prospective study included 50 female patients. All of them presented with pelvic floor dysfunction. Static and dynamic MRI were performed for all patients after injection of 120-150 ml of intrarectal gel and voiding $2 \mathrm{~h}$ before examination. Dynamic MRI was performed at rest, squeezing, straining phases, and during defecation.

Results: MR defecography can detect posterior compartment pathology with high sensitivity and specificity. We found anterior rectocele in 26 patients (52\%). Rectocele incidence was analyzed and compared to postoperative reports, and the receiver operator curve (ROC) was calculated that showed area under the curve (AUC) of 0.998. The cut-off value of $1.95 \mathrm{~cm}$ gives a sensitivity of $96.4 \%$ and specificity of $100 \%$ during straining. The percentage of anismus was 26\%, rectorectal intussusception 52\%, anal prolapse types (rectoanal intussusception $14 \%$ and external prolapse $8 \%$ ), and peritoneocele $34 \%$.
\end{abstract}

Conclusion: MRI is a valuable imaging modality that can be used to diagnose pelvic floor disorders and does not involve the risk of exposure to ionizing radiation. It can direct the surgical procedure and thus improve the postoperative results and decrease the rate of recurrence due to missed pathology.

Keywords: MRI, Defecography, Prolapse

\section{Background}

Pelvic floor dysfunction is a common health problem especially among women that represents a significant cause of morbidity and reduction in quality of life with increasing frequency during the last few years. Its current prevalence worldwide ranges from 18 to $50 \%$. The pelvic floor is made up of various muscles, ligaments, and connective tissues that support the pelvic organs. Damage to any of these structures may lead to pelvic floor dysfunction that may lead to abnormalities

\footnotetext{
*Correspondence: gamaldina2012@gmail.com

'Department of Radiodiagnosis, Faculty of Medicine, Mansoura University Hospitals, Mansoura, Egypt

Full list of author information is available at the end of the article
}

of bowel and bladder emptying and storage with or without associated pelvic pain [1].

The common symptoms include constipation, straining, lower back pain, urinary urgency, frequency and hesitancy, dyspareunia, and pelvic floor spasm [2]. Conventional defecography is considered the standard in the diagnosis of pelvic floor disorders specially the posterior compartment [3].

MR defecography has become a widely accepted imaging modality for the evaluation of pelvic floor disorders. With rapid development in MR imaging technology, MR defecography is now a valuable tool for the diagnosis of complex pelvic floor disorders and is favorable in several aspects compared to conventional proctography. MR defecography allows for the

\section{Springer Open}

(c) The Author(s). 2020 Open Access This article is licensed under a Creative Commons Attribution 4.0 International License, which permits use, sharing, adaptation, distribution and reproduction in any medium or format, as long as you give appropriate credit to the original author(s) and the source, provide a link to the Creative Commons licence, and indicate if changes were made. The images or other third party material in this article are included in the article's Creative Commons licence, unless indicated otherwise in a credit line to the material. If material is not included in the article's Creative Commons licence and your intended use is not permitted by statutory regulation or exceeds the permitted use, you will need to obtain permission directly from the copyright holder. To view a copy of this licence, visit http://creativecommons.org/licenses/by/4.0/. 


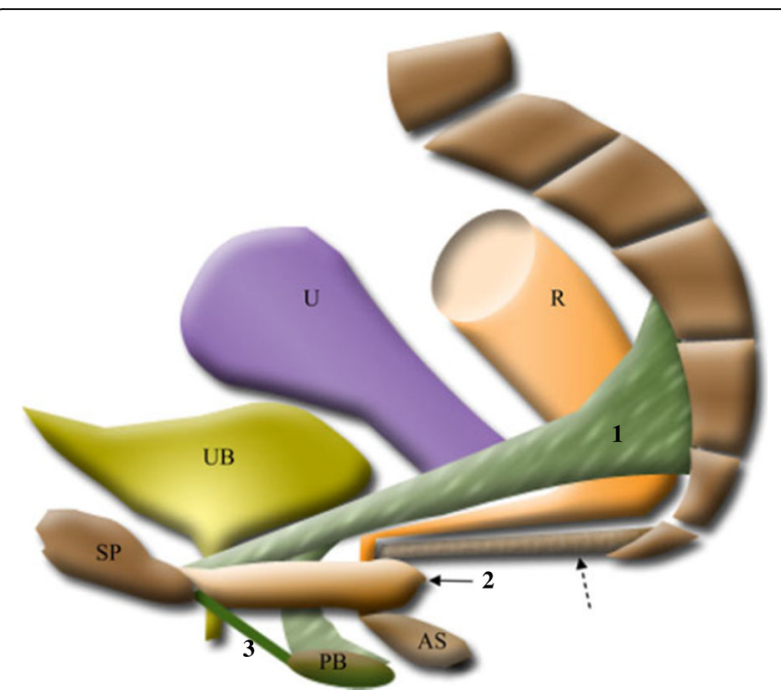

Fig. 1 Three-dimensional schematic drawing of the component of the pelvic floor integrated into a multilayer system from cranial to caudal consisting of (1) the endopelvic fascia, giving support to the uterus and upper vagina; (2) the pelvic diaphragm, including the puborectalis (solid arrow) and iliococcygeus (dashed arrow); and (3) urogenital diaphragm. AS anal sphincter complex, PB perineal body, $\mathbf{R}$ rectum, SP symphysis pubis, $\mathbf{U}$ uterus, UB urinary bladder [5]

visualization of all pelvic floor compartments in static and dynamic fashion [1].

The pelvic floor acts as a support mechanism to prevent organ prolapse and continence mechanism to urethral, anal, and vaginal orifices (in female), with realtime assessment of the evacuation process. The pelvis is divided into three compartments: anterior, middle, and posterior compartments-the anterior compartment contains the urinary bladder and urethra and supporting system; the middle compartment contains the uterus, cervix, vagina, and support system; and the posterior compartment contains the anorectum and support system [4]. The female supporting structures consist of a complex network of the fascia, ligaments (fascial condensation), and muscles attached to the pelvic bone (Fig. 1). These structures form three contiguous layers from a superior to an inferior location as follows:

1. The endopelvic fascia

2. The pelvic diaphragm

3. The urogenital diaphragm

The endopelvic fascia is divided into three levels as follows: Level I (suspension): The cephalic $2-3 \mathrm{~cm}$ of the vagina is suspended from above by the long connective tissue fibers of the upper paracolpium [5].

Level II (attachment): In the midportion of the vagina, the paracolpium becomes shorter and attaches the vaginal wall more directly to the arcus tendinous fascia

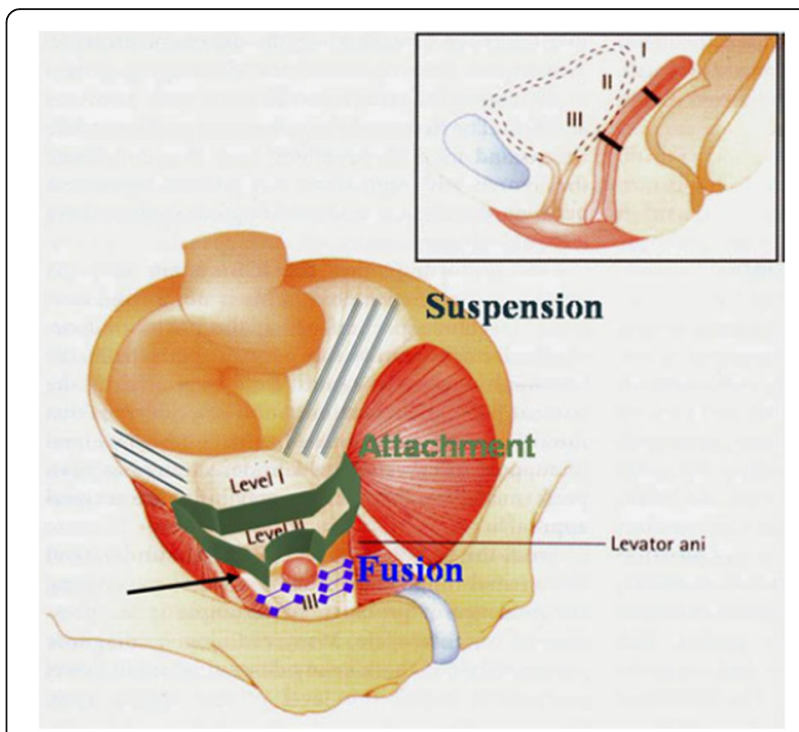

Fig. 2 Levels of endopelvic fascia [5]

at the lateral pelvic wall. This attachment stretches the vagina transversely between the bladder and rectum and has functional significance; the structural layer that supports the bladder (the pubocervical fascia) is composed of the anterior vaginal wall and its attachment through the endopelvic fascia to the pelvic wall [5].

Level III (fusion): Near the introitus, the vagina is blended laterally to the levator ani and posteriorly to the perineal body, whereas anteriorly, it fuses with the urethra. At this level, which corresponds to the region of the vagina that extends from the introitus to $2-3 \mathrm{~cm}$ above the hymenal ring, there is no intervening paracolpium between the vagina and its adjacent structures, contrary to the situation at levels I and II [5].

The pelvic diaphragm includes the levator ani muscle and coccygeus muscle. The levator ani is composed of the pubococcygeus muscle (medially) and iliococcygeus muscle (laterally). The medial border of the pubococcygeus is subdivided into pubourethralis, pubovaginalis, puborectalis, and puboanalis, and they are collectively called pubovisceralis; the urethral portion forms part of the periurethral muscles, and the vaginal and anorectal portion inserts into the vaginal wall, perineal body, and external anal sphincter; the puborectalis portion passes behind the rectum and fuses with its corresponding part from the opposite side to form a sling behind the anorectum; and the most posterior part of the pubococcygeus attaches to the coccyx (Fig. 2). The pelvic floor muscles have two essential functions as follows:

1. They provide support to the pelvic viscera.

2. Constrictor and continence function to the urethra, vagina, and anal canal. 

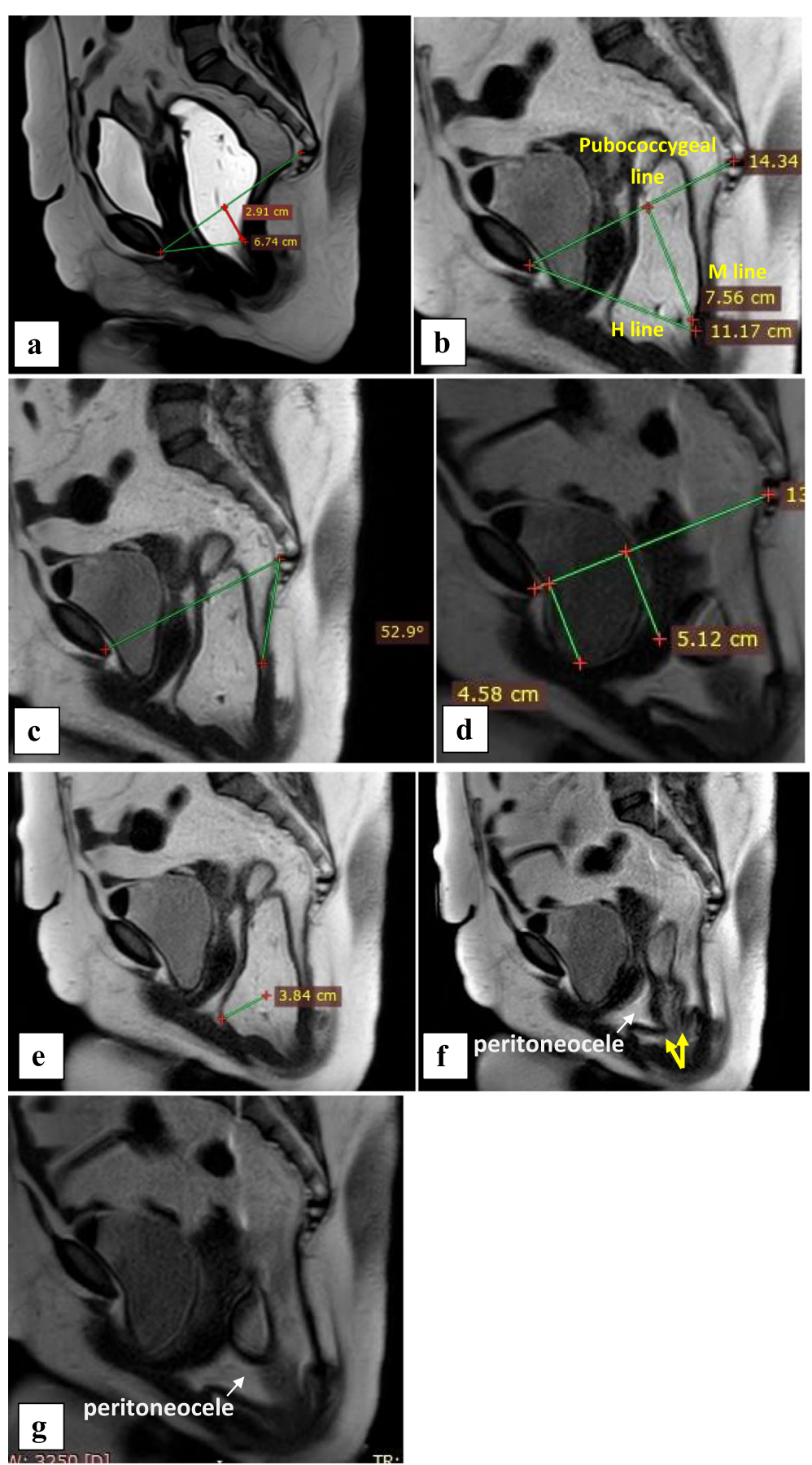

Fig. 3 Case no. 1: A 32-year-old female presented with incontinence to gases and stool 1 year ago and has a history of four vaginal deliveries went for T2W MRI — sagittal view—during rest $(\mathbf{a})$, during straining $(\mathbf{b}, \mathbf{c})$, and during defecation $(\mathbf{d}-\mathbf{g})$. During straining, there was a marked enlargement of levator hiatus $(\mathrm{H}$ line $=11.17 \mathrm{~cm})$, marked pelvic floor relaxation $(\mathrm{M}$ line $=7.56 \mathrm{~cm})(\mathbf{b})$, levator plate angle $=52.9$ degree $(\mathbf{c})$, moderate bladder base descent, moderate uterine, vaginal vault prolapse, and anterior Rectocele $3.84 \mathrm{~cm}$ with peritoneocele $(\mathbf{d}, \mathbf{e})$. During the defecatory phase, there was a progressive intrarectal and the intraanal prolapsed (yellow arrows in image $\mathbf{f}$ ) and peritoneocele become more evident (g) 


\section{Urogenital diaphragm (perineal membrane)}

The urogenital diaphragm presents over the anterior pelvic outlet below the pelvic diaphragm. It closes the levator hiatus, supports and acts as a sphincter-like effect at the distal vagina, provides support to the distal urethra, and gives continence.

\section{Aim of the work}

To evaluate the role of static MRI and dynamic MR defecography in the diagnosis of pelvic floor dysfunction.

\section{Methods}

Type of study

This is a prospective case series study.

\section{Duration of the study}

The duration of this study is 36 months.

\section{Inclusion criteria}

Any patient with rectal outlet obstruction or obstructed defecation, recurrent pelvic organ prolapse, pelvic pain and sense of pelvic heaviness, urinary or fecal incontinence, and dyssynergic defecation (anismus).

\section{Exclusion criteria}

Patients with a cochlear implant, or with clips used for brain aneurysm, or with cardiac defibrillators and pacemakers, or metal coils placed within blood vessels, or patients suffered from claustrophobia and nulliparous women were excluded.

\section{Consent}

Every patient signed on informed written consent including the examination steps, sharing in the research protocol and the approval on publishing the results.

\section{Ethical approval}

The study received an ethical committee approval from our Institution's Research Board. The reference number is MD/134.

\section{Technique of MR}

The study was conducted on 1.5 Tesla MRI (Philips MR Ingenia), every patient after signing down informed consent went for colonic preparation, and cleansing enema was done and asked not to void for $2 \mathrm{~h}$ before doing the study. Then, the study starts by introducing $120-150 \mathrm{ml}$ of ultrasonographic gel into the rectum by using a $50-\mathrm{ml}$ wide nozzle syringe, no oral or IV contrast is needed, and
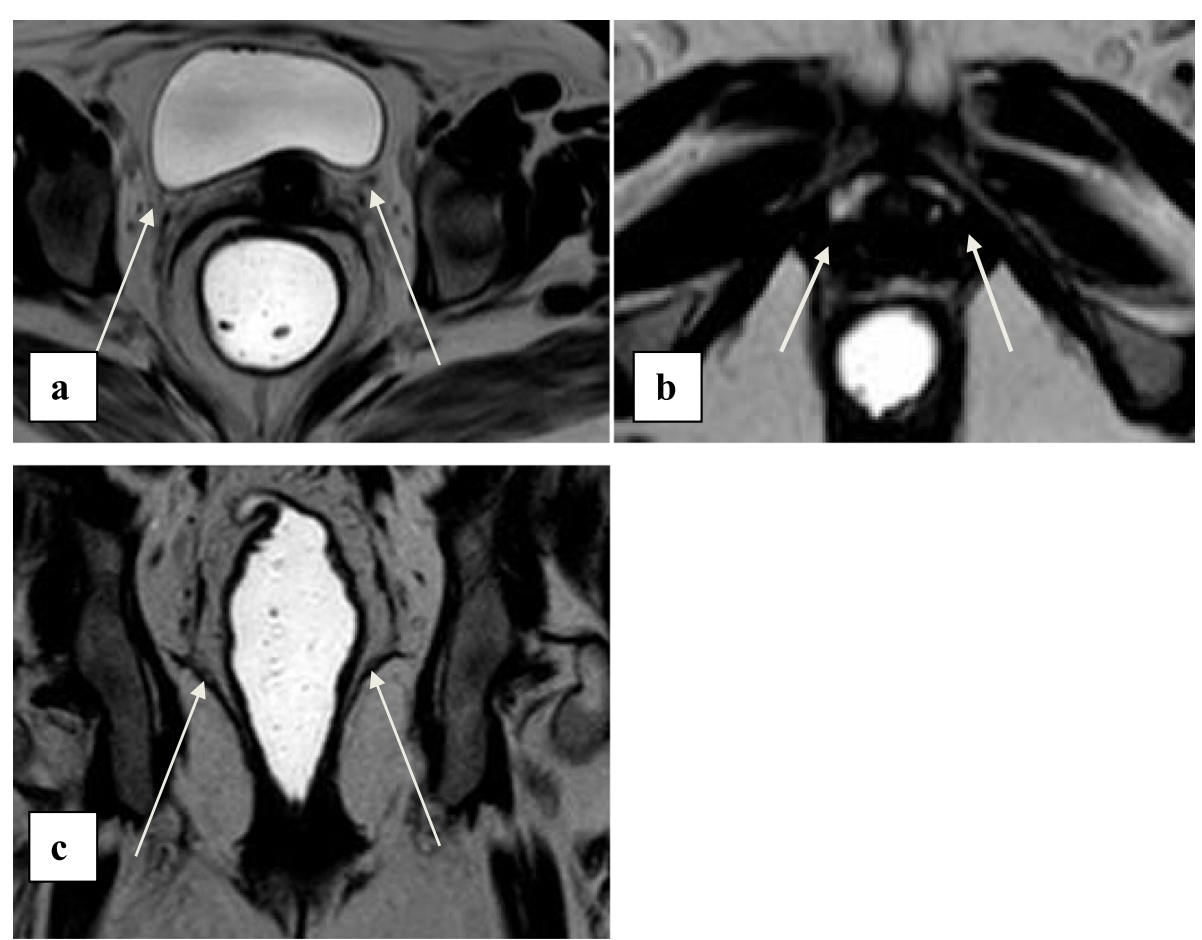

Fig. 4 Case no. 1: Static MRI T2W axial $(\mathbf{a}, \mathbf{b})$ and coronal (c) images show mild bilateral paravaginal level I and II endopelvic fascial defects more on the right side and widening of pelvic hiatus (white arrows in image a). Level III endopelvic fascial defect (dropping mustache sign) with a defect of urethral ligaments on RT side (white arrows in image $\mathbf{b}$ ); there was a defect in iliococcygeus muscle attachment on both sides more on the left side (white arrows in image c) 
the patient is instructed about the procedure and how and when to squeeze, strain, or defecate.

The patient's position is to lie on a supine position with a phased array coil placed low around the pelvis. The patient can bend his knees to facilitate defecation after wearing a pad to avoid table contamination.

\section{Imaging protocol}

Static images of the pelvis are acquired in three planes using T2-weighted turbo spin-echo (TSE) sequences (TR/TE 5000/132; FOV 240-260 mm, slice thickness $5 \mathrm{~mm}$, gap 0.7 $\mathrm{mm}$, number of signals acquired 2, flip angle $90^{\circ}$, matrix 512 _ 512, and acquisition time $3.12 \mathrm{~min}$ for each sequence).
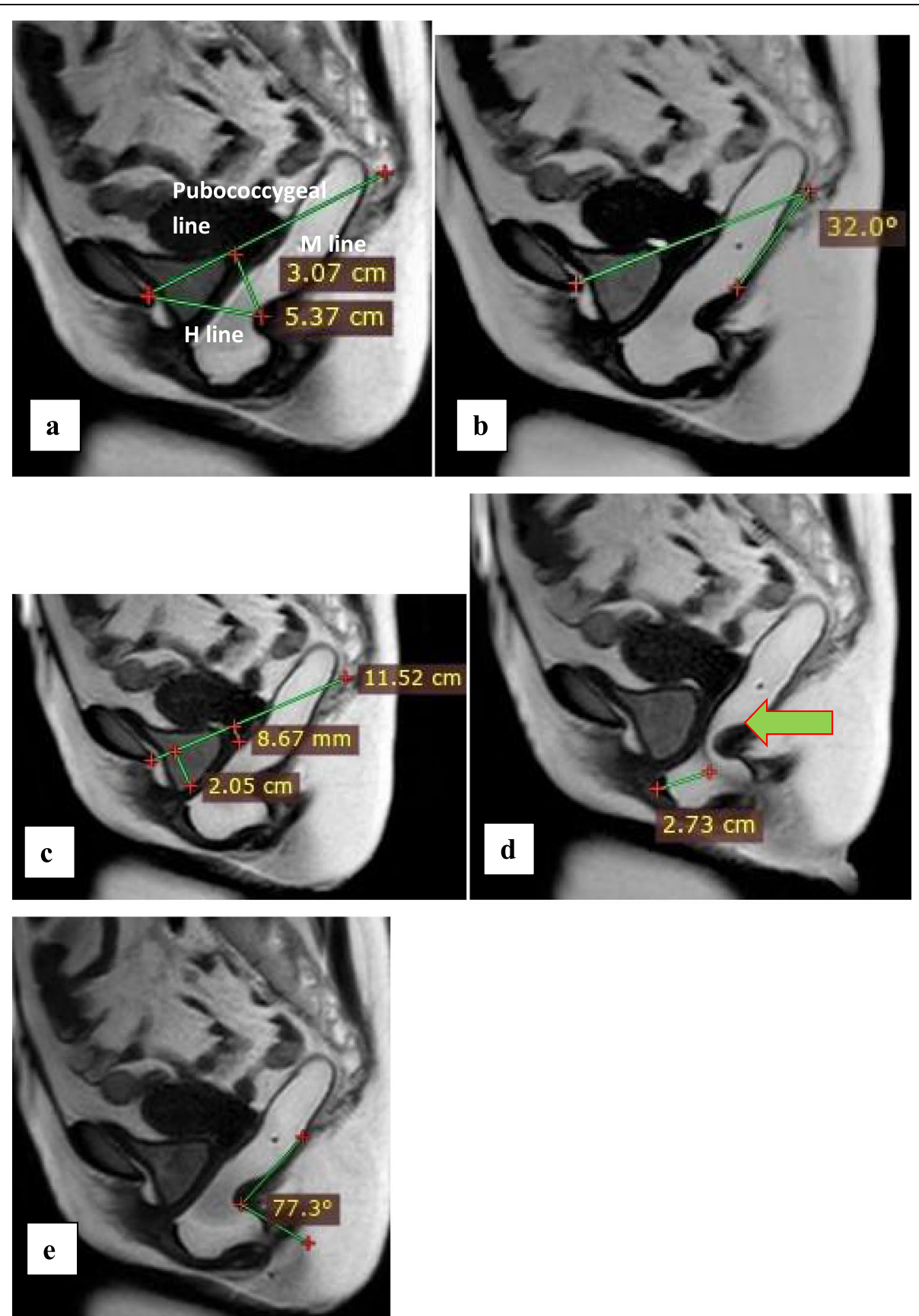

Fig. 5 Case no. 2: A 30-year-old female presented with obstructed defecation, stress urinary incontinence, and history of four vaginal deliveries went for T2W MRI—sagittal view_dynamic MRI images. Straining phase shows normal levator hiatus ( $\mathrm{H}$ line $=5.37 \mathrm{~cm}$ ), mild pelvic floor relaxation $(\mathrm{M}$ line $=3.07 \mathrm{~cm})(\mathbf{a})$, caudal angulation of levator plate, levator plate angle $=32$ degree $(\mathbf{b})$, mild bladder base descent, no significant vaginal vault descent $(\mathbf{c})$, anterior rectocele 2.73 with paradoxical contraction of puborectalis muscle (green arrow) (d), narrow anorectal angle $\left(77.3^{\circ}\right)$, inadequate rectal evacuation, and residual intrarectal gel during defecatory phase (e) 
In patients reporting anal incontinence or obstructed defecation, the following sequences are added for assessment of the anal sphincter complex: T2-weighted BFFE images of the anal sphincter complex are obtained (9.0/ 4.0, FOV $220 \mathrm{~mm}$, section thickness $3 \mathrm{~mm}$, number of signals acquired 8, flip angle $45^{\circ}$, matrix 512 _ 512, acquisition time $2.12 \mathrm{~min}$ ). In this sequence, section orientation is parallel (in the coronal plane) and perpendicular (in the axial plane) to the plane of the anal canal.

\section{Acquisition of dynamic MRI sequences}

Dynamic sequences are performed in the sagittal, axial, and coronal planes using a balanced fast-field echo (BFFE) sequence (TR/TE $850 / 120 \mathrm{~ms}$, FOV $444 \mathrm{~mm}$, slice thickness $6-7 \mathrm{~mm}$, gap $0.7 \mathrm{~mm}$ ).

In each plane, five slices during four phases are acquired; each phase takes $10 \mathrm{~s}$, the following four phases are acquired:

1. With the patient at rest.

2. During contraction of the pelvic floor (the patient is instructed to squeeze her buttocks as if trying to prevent the escape of urine).

3. During a repeated maximum straining sequence to ensure a maximal Valsalva maneuver (the patient is instructed to bear down as much as she can, as though she is constipated and trying to defecate).

4. During defecation in the sagittal plane (the patient is asked to evacuate the injected intrarectal gel).

\section{Dynamic magnetic resonance imaging Diagnostic criteria}

Dynamic MRI is best evaluated on midsagittal true fast imaging dynamic evacuation sequences and on sagittal, axial, and coronal images during maximum straining, when the pelvic organ descent should be greatest. The following are the criteria measured during maximum straining.

\section{Sagittal plane}

1. The pubococcygeus line (PCL) is used as the reference line. It extends from the inferior border of the symphysis pubis anteriorly to the last coccygeal joint posteriorly. The descent of pelvic organs is measured along a perpendicular line from the organ to the PCL, and this should be measured both at rest and during maximum straining.

- Prolapse severity can be easily graded according to the "rule of three":

- Mild prolapse of an organ below the PCL by $3 \mathrm{~cm}$

- Moderate prolapse of 3-6 cm
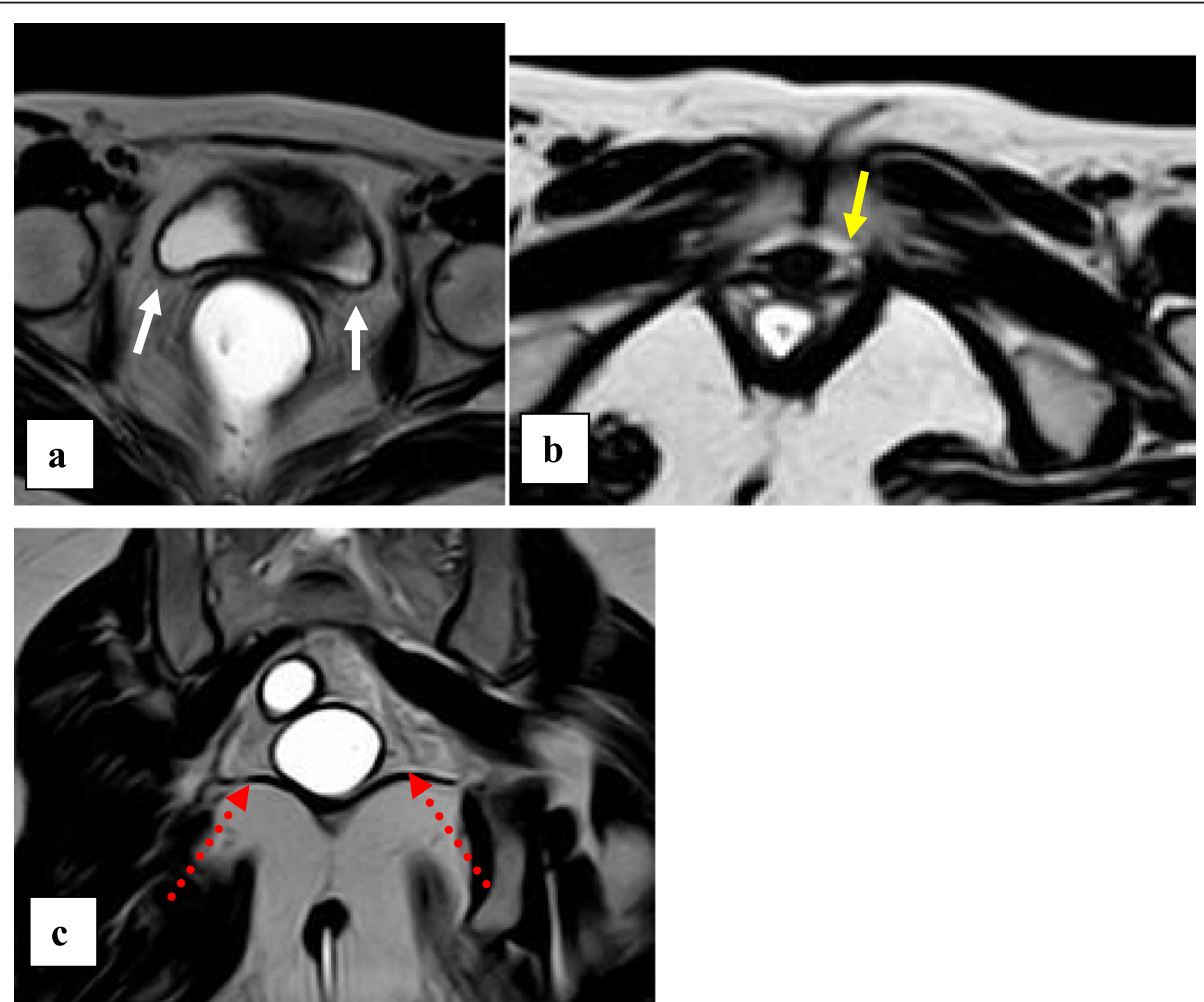

Fig. 6 Case no. 2: Static MRI images. Images show left-sided minimal paravaginal level I and II endopelvic fascial defect (white arrows in image a), deformation of urethral ligaments on the left side (yellow arrow in image b), and coronal view shows intact levator ani muscles on both sides (red dashed arrows in image c) 
- Severe prolapse more than $6 \mathrm{~cm}$

- Other measurements in the sagittal plane during maximum straining include the following:

2. The $\mathbf{H}$-line extends from the inferior aspect of the pubic symphysis to the anorectal junction. It represents the most caudal part of the levator ani group (puborectalis muscle) and allows the assessment levator hiatus in AP diameter during straining. A diameter greater than 6 $\mathrm{cm}$ is considered abnormal.

3. The M-line is dropped as a perpendicular line from the PCL to the posterior aspect of the $\mathrm{H}$-line. It represents the measure of the muscular pelvic floor descent (pelvic floor relaxation). And the length that exceeds 2 $\mathrm{cm}$ is abnormal.

4. The levator plate angle is enclosed between the levator plate and the PCL, normally measured $11.7 \pm 5$.
The posterior compartment is assessed for anorectal descent and other pathologies as rectocele, peritoneocele, enterocele, intussusception, prolapse, anorectal angle, and anismus.

The MRI images were interpreted by 2 separate consultants who worked separately from each other, and some patients performed a conventional defecography to be used as a reference in case of image interpretation conflicts (Figs. 3, 4, 5, 6, 7, and 8).

\section{Results}

This prospective study was performed on 50 female patients between $5 / 2015$ and 6/2018 using MRI defecography, and the mean age of the patients was 38.7 years. Patients had different symptoms such as pelvic pain, stress UI, obstructed defecation, and or fecal incontinence. The most common symptoms were obstructed
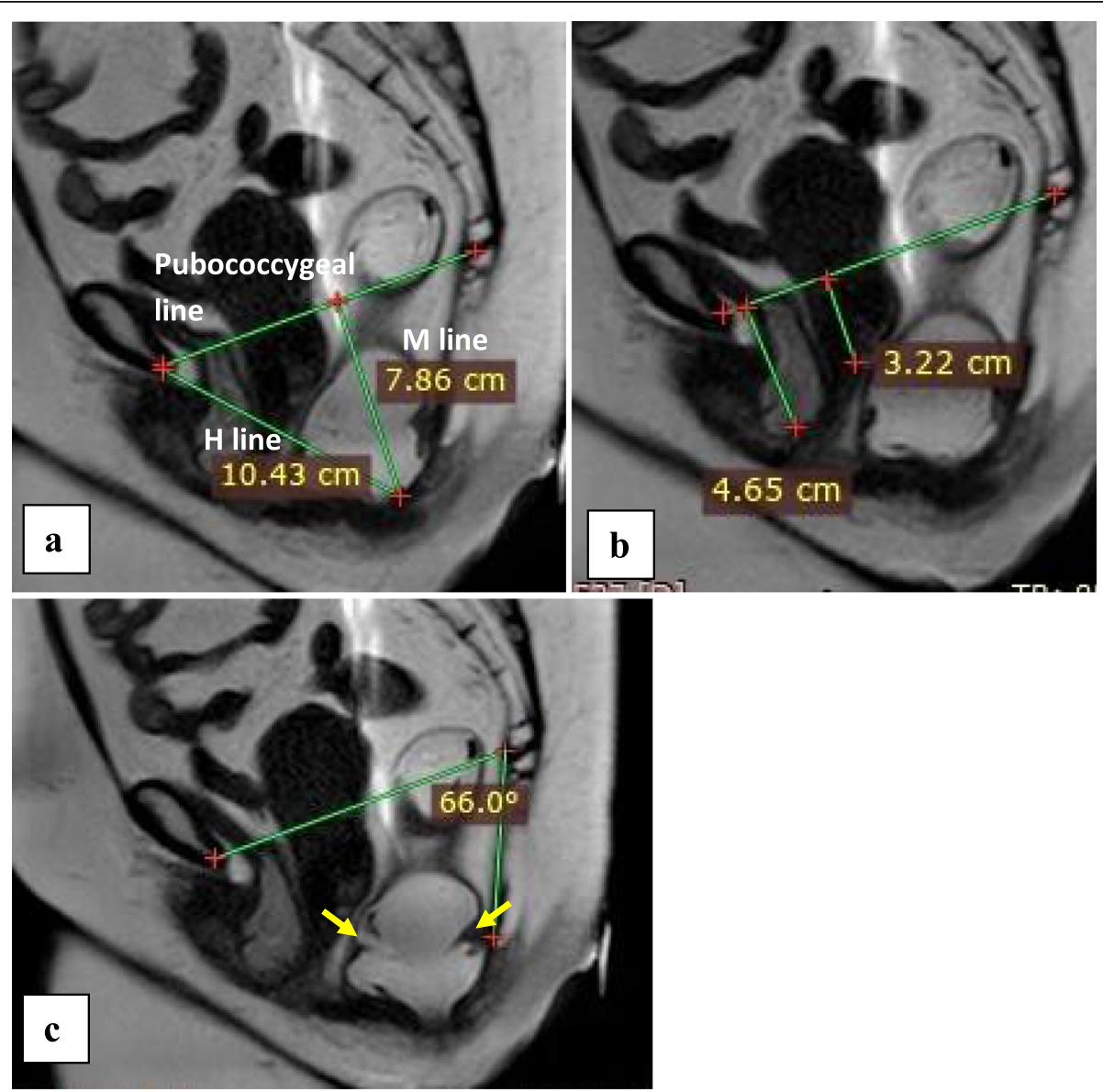

Fig. 7 Case no. 3: A 41-year-old female presented with fecal incontinence, obstructed defecation, stress urinary incontinence, and history of five vaginal deliveries went for T2W MRI — sagittal view_dynamic MRI images. Dynamic MRI imaging during straining showed marked levator hiatus enlargement $(\mathrm{H}$ line $=10.43 \mathrm{~cm}$ ), marked pelvic floor relaxation $(\mathrm{M}$ line $=7.86 \mathrm{~cm})(\mathbf{a})$, moderate bladder base descent and urethral hypermotility, moderate cervical and vaginal vault descent (b), and marked caudal angulation of levator plate, levator plate angle $=66^{\circ}$. Progressive low intrarectal intussusception (yellow arrows) and open anal canal with inadequate rectal evacuation and residual intrarectal gel during defecatory phase $(\mathbf{c})$ 
defecation $84 \%$, stress UI $38 \%$, and fecal incontinence $36 \%$.

The obstetric history of the patients showed a previous history of three (19 patients) or four (17 patients) previous vaginal deliveries (34 patients).

Every patient was tested during rest, squeezing, straining and defecation, $\mathrm{H}$ lines, and $\mathrm{M}$ lines were measured in all cases during rest and straining as shown in box plots below; the $\mathrm{H}$ line during rest was (median $=5, \mathrm{IQR}$ $=1.6$ ) and during straining was (median $=6.95, \mathrm{IQR}=$ 2.4 ), while the $M$ line during rest was (median $=1.75$, $\mathrm{IQR}=1.08$ ) and during straining was (median $=4.5$, $\mathrm{IQR}=2.13$ ) (Fig. 9).

MR examination of the posterior compartment was done during rest and during straining, and the incidence of rectocele, peritonocele, and enterocele were represented in Table 1 . They were $52 \%, 34 \%$, and $4 \%$ respectively. Anismus $26 \%$, rectorectal intussusception $52 \%$, and anal prolapse types (rectoanal intussusception 14\% and external prolapse 8\%) were represented.

Rectocele incidence was analyzed and compared to postoperative reports, and the receiver operator curve (ROC) was calculated that showed area under the curve (AUC) 0.998 . The cut-off value of $1.95 \mathrm{~cm}$ gives a sensitivity of $96.4 \%$ and specificity of $100 \%$ during straining (Fig. 10).

Static MRI was used to detect endopelvic fascial defects (levels I, II, and III), which were examined at axial T2 images and also defects in levator ani muscle (iliococcygeus muscle which was examined at coronal T2 images, puborectalis muscle which was examined at axial T2 images).

Level I and II fascial defects were $72 \%$ where 36 patients had a fascial defect, 34 patients had paravaginal endopelvic fascial defect, and 2 patients had a central fascial defect, while level III fascial defect was 30\% (15 patients).

Levator ani (iliococcygeus and puborectalis) muscle states were assessed during the study. As regards
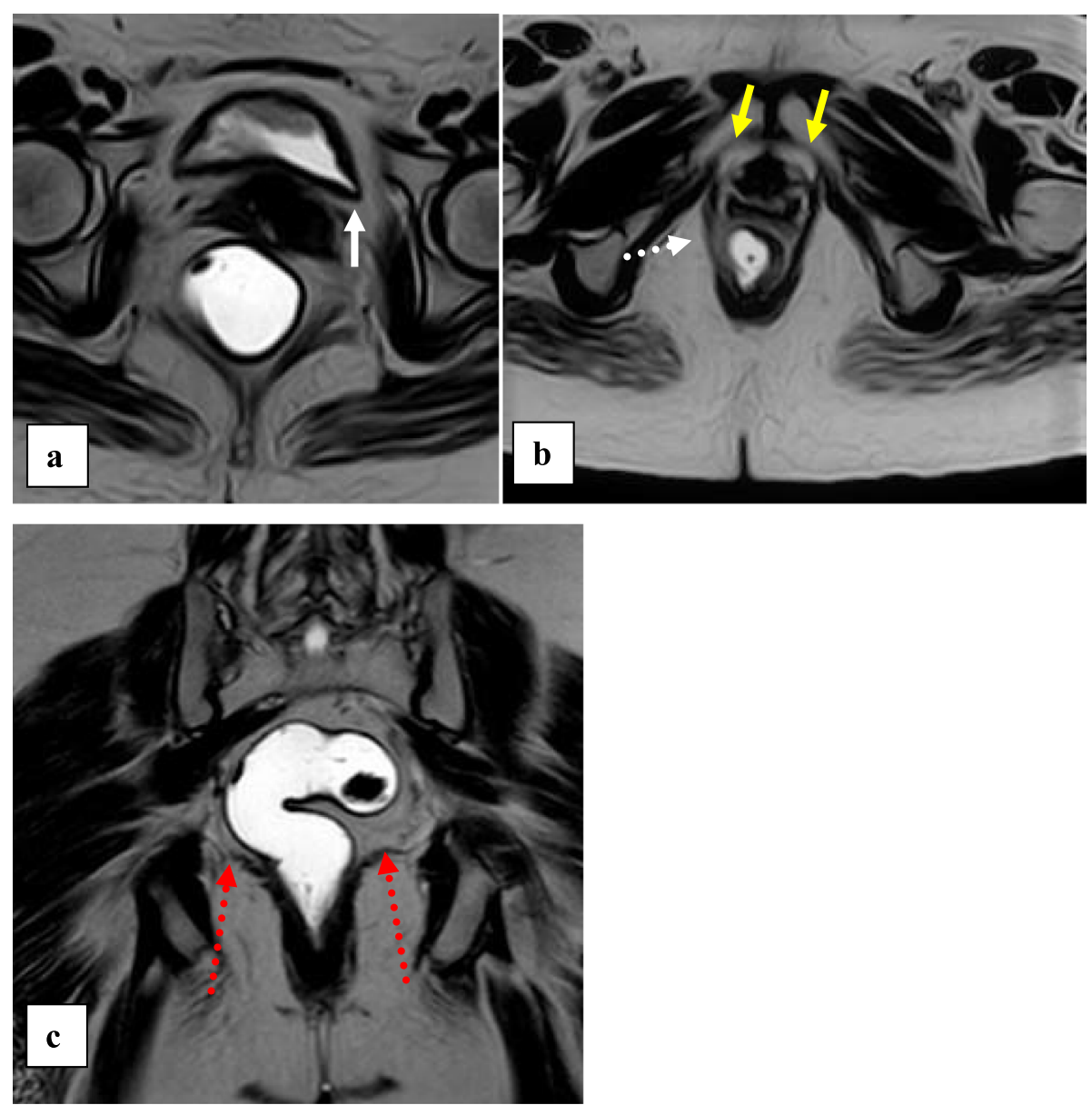

Fig. 8 Case no. 3: Static T2W images. Show left-sided mild paravaginal level I and II endopelvic fascial defects (white arrow in image a). Level I endopelvic fascial defect (dropping mustache sign) (yellow arrows), atrophy and defect of the right puborectalis muscle and internal anal sphincter on the right side (dashed white arrow) (b), and coronal view shows atrophy and waviness of levator ani muscle on both sides (dashed red arrows in image $\mathbf{c}$ ). 

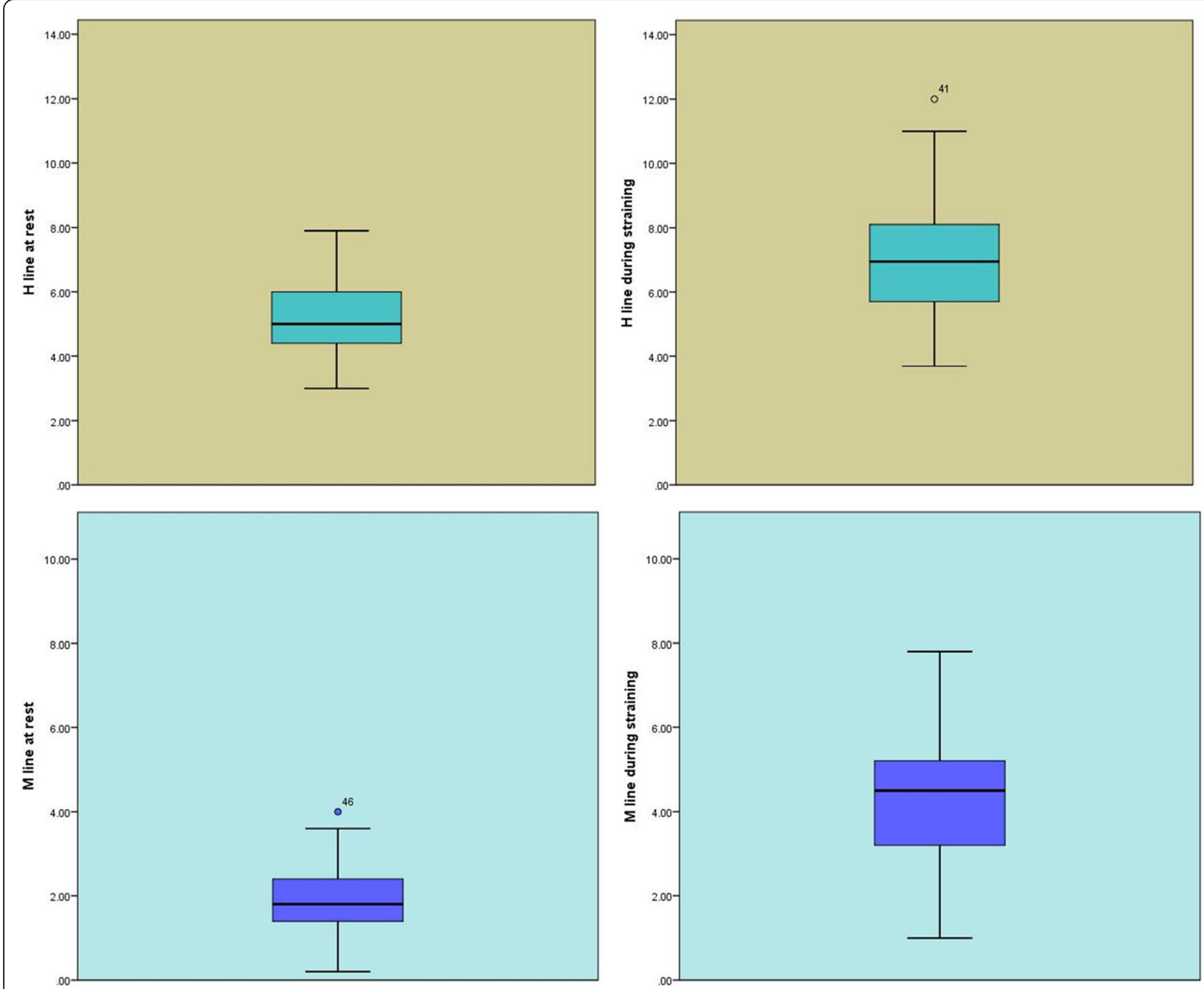

Fig. 9 The $\mathrm{H}$ line and $\mathrm{M}$ line measurements at rest and during straining

iliococcygeus muscle, 19 patients had intact iliococcygeus muscle, while 20 patients had iliococcygeus muscle avulsion or defect, 9 patients had atrophy of the muscle, and 2 patients had scarring of the muscle.

As regards the state of the puborectalis muscle, $28 \mathrm{pa}$ tients (56\%) had normal puborectalis muscle, while 22 patients (44\%) had a puborectalis defect, atrophy, or scarring.

Anorectal angles also were measured during straining, and when compared in patients with anismus, it was lower than patients without anismus with significant difference $(P=0.000)$ and also there was a significant decrease of anorectal angle in patients with obstructed defecation if compared to patients with no obstructed defecation $(P=0.0049)$ (Table 2$)$.

\section{Discussion}

MRI defecography can overcome certain limitations of conventional defecography and ultrasonography as all three compartments can be well visualized without the need for additional installation of contrast into the anterior and middle compartments, and therefore, many other disorders which can affect the management of the patients can be identified [6].

Table 1 Posterior compartment disorders

\begin{tabular}{lll}
\hline Disorder & Frequency/total & Percentage \\
\hline Rectocele & $26 / 50$ & 52 \\
Peritonocele & $17 / 50$ & 34 \\
Enterocele & $2 / 50$ & 4 \\
Anismus & $13 / 50$ & 26 \\
Intussusception & $26 / 50$ & 52 \\
Intraanal prolapse & $7 / 50$ & 14 \\
External prolapse & $4 / 50$ & 8 \\
Mucosal prolapse & $2 / 50$ & 4 \\
\hline
\end{tabular}




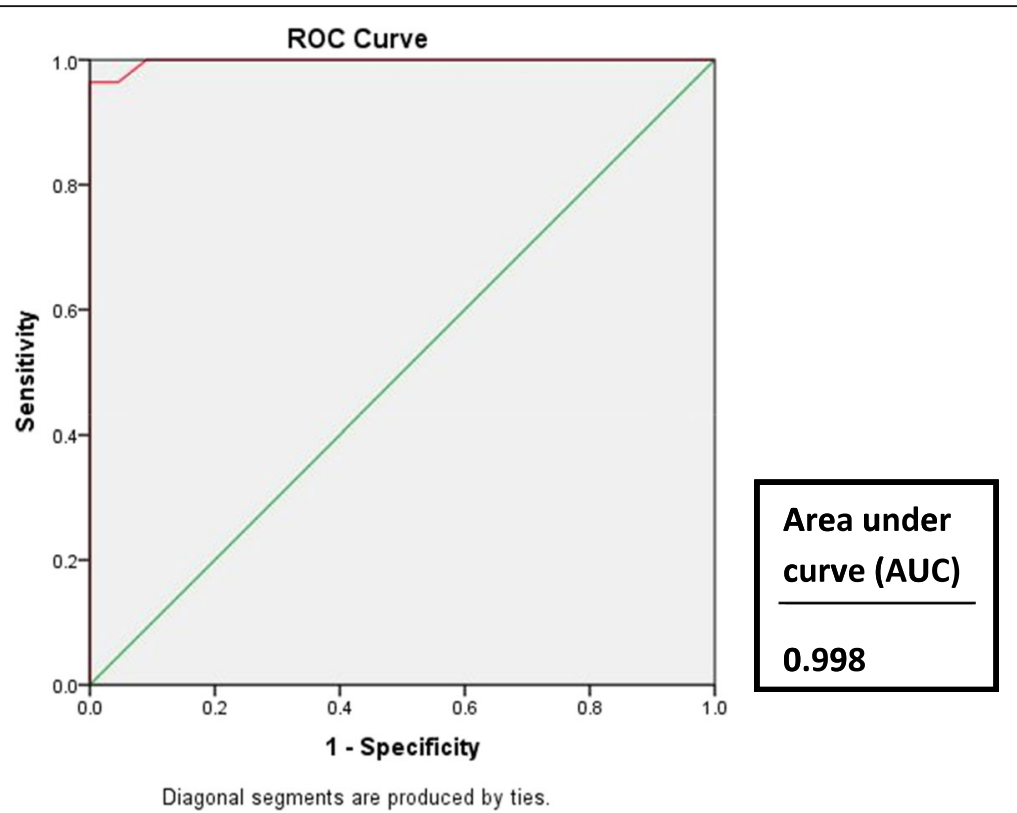

Fig. 10 ROC curve. Twenty-six patients had intussusception, two of them had intussusception at MR and were missed on conventional defecography; these intussusceptions were mucosal prolapse

Static and dynamic MR defecography can provide anatomic and functional information with a good evaluation of the pelvic fascia, ligaments, muscles, and the function of anorectal and pelvic muscles with no risk of exposure of ionizing radiation and high patient compliance [7].

The current aim in this study is to detect the role of static and dynamic MRI in patients with pelvic floor dysfunction, and we aim to introduce this test and make it available for patients at our institution.

Static MRI gave information about endopelvic fascia which was examined at axial T2WI as follows: $72 \%$ of patients had level I and II endopelvic fascial defects which were evident by central or paravaginal sagging of posterior wall of the urinary bladder and $30 \%$ of the patients presented with level III fascial defect detected by dropping mustache sign and loss of $\mathrm{H}$ shape of the vagina, and also, state of the muscles was detected as follows: iliococcygeus muscle was normal in about $39 \%$ of patients, $17 \%$ showed atrophy, $40 \%$ showed defect, and $4 \%$ showed scarring. Puborectalis muscle was evaluated at axial T2WI, was normal in 56\%, and showed a defect in $44 \%$ of the patient. LA avulsion was easily recognized on MRI and we found that they were associated with a higher risk of prolapse and this matched with Pizzoferrato et al. [8].

Dynamic MRI was done during rest, squeezing, straining, and defecation; $\mathrm{H}$ and $\mathrm{M}$ lines were measured; they were significant increase during straining in the patients with pelvic floor dysfunction (especially fecal incontinence); and this was in agreement with Schawkat et al. [1].
Flusberg et al. [9] observed that the additional anterior, middle, and posterior compartment descents were seen during defecation compared to the straining phase; the authors concluded that looking at the pelvic floor descents only during straining may underestimate the findings as a higher degree of pelvic floor descent and additional pelvic floor pathologies, and this matches with our study that as more descent detected at defecation rectocele, peritoneocele becomes more evident and additional pathology as loss of urine could be detected.

Posterior compartment findings were detected in 52\% of patients with rectocele, $34 \%$ with peritoneocele, $4 \%$ with enterocele, $26 \%$ with anismus, $52 \%$ with rectorectal intussusception, $14 \%$ with rectoanal intussusception, and $8 \%$ presented with external prolapse; rectocele incidence was analyzed and compared to postoperative reports; and ROC curve was calculated that showed AUC 0.998. The cut-off value of 1.95 can give sensitivity of $96.4 \%$ and specificity of $100 \%$ during straining.

Conventional defecography has been used for years, the introduction of MR defecography initiated a

Table 2 Effect of anismus and obstructed defecation on anorectal angle

\begin{tabular}{llll}
\hline & Anismus & No anismus & $t^{2}$ \\
\hline $\begin{array}{l}\text { Anorectal angle } \\
\text { mean }\end{array}$ & $86.6 \pm 14.9$ & $125.8 \pm 21.2$ & 0.000 \\
& $\begin{array}{l}\text { Obstructed } \\
\text { defecation }\end{array}$ & $\begin{array}{l}\text { No obstructed } \\
\text { defecation }\end{array}$ & $t^{2}$ \\
$\begin{array}{l}\text { Anorectal angle } \\
\text { mean }\end{array}$ & $110.6 \pm 25.1$ & $140.1 \pm 19.4$ & 0.0049 \\
\hline
\end{tabular}


controversy about the advantage of MR defecography and its cost-effectiveness compared with conventional techniques, and studies have shown that functional MR imaging with rectal contrast either have a statistically similar frequency of the pelvic organ prolapse or is superior to its fluoroscopic center part, especially for picking up anterior and middle compartment disorders and rectocele [10]. This matches our study and this was in agreement with Lalwani et al. [6].

Pilkington et al. [11] showed that rectoceles were extremely common, and this matches our study where rectoceles were the commonest pathology in the posterior compartment. The current study found that MR defecography can diagnose rectocele of the sensitivity of about $96 \%$ and specificity of about $100 \%$, and this is in agreement with Lienemann et al. [12] that showed that MR can diagnose rectocele with sensitivity and specificity of about $69 \%$ and $96 \%$ which was higher than barium defecography.

We found in our study that MRI has high sensitivity in the detection of peritoneocele and enterocele and can differentiate between contents with no selective opacification while the capability of conventional defecography is limited with the need for bowel opacification; this is in agreement with Lalwani et al. [6]. Also, Cappabianca et al. [13] published that sensitivity and specificity of MRI in the detection of enterocele were $82 \%$ and $100 \%$, respectively. All previous studies found that MR defecography can differ between mucosal versus full-thickness intussusception, and this matches the current study.

The current study had certain limitations as MR defecography was performed in the supine position. This may not be fully representative of the defecation process in the physiologic sitting position. However, most institutions do not have access to an open configuration MR, and therefore, the reported results are clinically relevant.

\section{Conclusion}

MRI is a valuable imaging modality that can be used to diagnose pelvic floor disorders and does not involve the risk of exposure to ionizing radiation. It can assess the three compartments of the pelvis. It is the image of modality in multi-compartmental pathologies that can direct the surgical procedure and thus improve the postoperative results and decrease the rate of recurrence due to missed pathology.

\section{Abbreviations}

3D: Three-dimensional; AP: Antero-posterior; FOV: Field of view;

IV: Intravenous; MR: Magnetic resonance; MRI: Magnetic resonance imaging; PCL: Pubococcygeal line; TE: Time to echo; TR: Time of repetition; TSE: Turbo spin echo; US: Ultrasound; Wl: Weighted image

Acknowledgements

None

\section{Authors' contributions}

DGA contributed to conceiving and designing the study, collecting the data, performing the statistical analysis, and writing the article. MA contributed to conceiving and designing the study, collecting the data, performing the statistical analysis, and writing the article. WMT contributed to conceiving and designing the study, collecting the data, performing the statistical analysis, and writing the article. AME contributed to conceiving and designing the study, collecting the data, performing the statistical analysis, and revising the article.MMS contributed to conceiving and designing the study, collecting the data, and revising and approval of the article. All authors have read and approved the submitted manuscript.

Funding

None.

\section{Availability of data and materials}

The data that support the findings of this study are available from the corresponding author, Dina G. Abdelzaher, upon reasonable request.

\section{Ethics approval and consent to participate}

The study received an ethical committee approval from the Mansoura Faculty of Medicine Institutional Research Board the reference number MD/ 134, and every patient has signed an informed written consent of the study protocol.

\section{Consent for publication}

Every patient has signed an informed written consent for publication.

\section{Competing interests}

None.

\section{Author details}

'Department of Radiodiagnosis, Faculty of Medicine, Mansoura University Hospitals, Mansoura, Egypt. ${ }^{2}$ Department of General Surgery, Faculty of Medicine, Mansoura University Hospitals, Mansoura, Egypt. ${ }^{3}$ Department of Vascular Surgery, Faculty of Medicine, Mansoura University Hospitals, Mansoura, Egypt.

Received: 27 November 2019 Accepted: 17 March 2020

Published online: 04 May 2020

\section{References}

1. Schawkat K, Heinrich H, Parker HL et al (2018) How to define pathologic pelvic floor descent in MR defecography during defecation? Abdom Radiol 43:3233-3240. https://doi.org/10.1007/s00261-018-1652-7

2. Darwish HS, Zaytoun HA, Kamel HA et al (2014) Assessment of pelvic floor dysfunctions using dynamic magnetic resonance imaging. Egypt J Radiol Nucl Med 45:225-229. https://doi.org/10.1016/j.ejrnm.2013.12.006

3. Bolog N, Weishaupt D (2005) Dynamic MR imaging of outlet obstruction. Rom J Gastroenterol 14:293-302

4. Chi TW-C, Chen S-H (2007) Dynamic magnetic resonance imaging used in evaluation of female pelvic prolapse: experience from nine cases. Kaohsiung J Med Sci 23:302-308. https://doi.org/10.1016/S1607-551X(09)70413-9

5. El Sayed RF (2017) How to perform and report magnetic resonance imaging for pelvic floor dysfunction: an interactive case-based approach. https://doi.org/10.1007/978-88-470-5659-6

6. Lalwani N, Moshiri M, Lee JH et al (2013) Magnetic resonance imaging of pelvic floor dysfunction. Radiol Clin North Am 51:1127-1139. https://doi.org/ 10.1016/j.rcl.2013.07.004

7. El Sayed RF, Alt CD, Maccioni F et al (2017) Magnetic resonance imaging of pelvic floor dysfunction - joint recommendations of the ESUR and ESGAR Pelvic Floor Working Group. Eur Radiol 27:2067-2085. https://doi.org/10. 1007/s00330-016-4471-7

8. Pizzoferrato A-C, Nyangoh Timoh K, Fritel X et al (2014) Dynamic magnetic resonance imaging and pelvic floor disorders: how and when? Eur J Obstet Gynecol Reprod Biol 181:259-266. https://doi.org/10.1016/j.ejogrb.2014.07. 025

9. Flusberg M, Sahni VA, Erturk SM et al (2011) Dynamic MR defecography: assessment of the usefulness of the defecation phase. Am J Roentgenol 196:394-399. https://doi.org/10.2214/AJR.10.4445 
10. Prasad R, Gelder K, Wiles R (2018) The patient's experience of defaecating proctography: comparing magnetic resonance with conventional fluoroscopy techniques. Radiography 25:24-27. https://doi.org/10.1016/j.radi. 2018.07.002

11. Pilkington SA, Nugent KP, Brenner J et al (2012) Barium proctography vs magnetic resonance proctography for pelvic floor disorders: a comparative study. Color Dis 14:1224-1230. https://doi.org/10.1111/j.1463-1318.2012. 02945.x

12. Lienemann A, Anthuber C, Baron A et al (1997) Dynamic MR colpocystorectography assessing pelvic-floor descent. Eur Radiol 7:13091317. https://doi.org/10.1007/s003300050294

13. Cappabianca S, Reginelli A, lacobellis F et al (2011) Dynamic MRI defecography vs. entero-colpo-cysto-defecography in the evaluation of midline pelvic floor hernias in female pelvic floor disorders. Int J Colorectal Dis 26:1191-1196. https://doi.org/10.1007/s00384-011-1218-4

\section{Publisher's Note}

Springer Nature remains neutral with regard to jurisdictional claims in published maps and institutional affiliations.

\section{Submit your manuscript to a SpringerOpen ${ }^{\circ}$ journal and benefit from:}

- Convenient online submission

Rigorous peer review

- Open access: articles freely available online

High visibility within the field

- Retaining the copyright to your article

Submit your next manuscript at $\boldsymbol{\nabla}$ springeropen.com 